proactive interference in dyslexia 1

Running head: proactive interference in dyslexia

\title{
Increased susceptibility to proactive interference in adults with dyslexia?
}

\author{
Louisa Bogaerts ${ }^{1}$, Arnaud Szmalec ${ }^{2}$, Wibke M. Hachmann ${ }^{3}$, Mike P.A. Page ${ }^{4}$, Evy \\ Woumans $^{1}$, \& Wouter Duyck ${ }^{1}$ \\ ${ }^{1}$ Ghent University, Ghent, Belgium \\ ${ }^{2}$ Université Catholique de Louvain, Louvain-la-Neuve, Belgium \\ ${ }^{3}$ University of Trento, Rovereto, Italy \\ ${ }^{4}$ University of Hertfordshire, Hatfield, UK
}

Correspondence Address:

Louisa Bogaerts

Department of Experimental Psychology

Ghent University

Henri Dunantlaan 2

B-9000 Ghent (Belgium)

E-mail: louisa.bogaerts@UGent.be

Tel.: +32-(0)9-264.64.39

WORD COUNT: 4000 
proactive interference in dyslexia 2

\begin{abstract}
Recent findings show that people with dyslexia have an impairment in serial-order memory. Based on these findings, the present study aimed to test the hypothesis that people with dyslexia have difficulties dealing with proactive interference in recognition memory. A group of 25 adults with dyslexia and a group of matched controls were subjected to a 2back recognition task, which required participants to indicate whether an item (mis)matched the item that had been presented 2 trials before. Proactive interference was elicited using lure trials in which the item matched the item in the 3-back position instead of the targeted 2-back position. Our results demonstrate that the introduction of lure trials affected 2-back recognition performance more severely in the dyslexic group than in the control group, suggesting greater difficulty in resisting proactive interference in dyslexia.
\end{abstract}

Keywords: dyslexia, proactive interference, serial-order processing, working memory, recollection 
proactive interference in dyslexia 3

\section{Introduction}

Dyslexia

Developmental dyslexia is a learning disorder characterized by persistent difficulties with reading and/or spelling (e.g., Lyon, Shaywitz, \& Shaywitz, 2003; Vellutino, Fletcher, Snowling, \& Scanlon, 2004). The influential phonological deficit hypothesis (e.g., Snowling, 2000) postulates that an impairment in the processing and representation of phonological information is the core deficit underlying dyslexia, responsible for the wide variety of language problems that are seen in the disorder. However, a consensus on the underlying cause of developmental dyslexia has not been reached (e.g., Pennington, 2006). First, there are instances where people with developmental dyslexia do not show a phonological impairment and nevertheless fail to achieve fluency in (word) reading (Paulesu et al., 2001; Wimmer, Mayringer, \& Landerl, 2000). Second, even though the hallmark of dyslexia is the persistent difficulty with reading and/or spelling, people with dyslexia also show deficits on various nonlinguistic cognitive processes, among which are working memory (WM; e.g., Smith-Spark \& Fisk, 2007), implicit learning (e.g., JiménezFernández, Vaquero, Jiménez, \& Defior, 2011; Pavlidou, Kelly, \& Williams, 2010; Vicari, Marotta, Menghini, Molinari, \& Petrosini, 2003), motor sequencing (e.g., De Kleine \& Verwey, 2009), and sensorimotor functioning (e.g., Stein, 2001, but see also Ramus, 2003).

Recently, Szmalec, Loncke, Page, and Duyck (2011) introduced a novel, integrative hypothesis, which proposes that both the linguistic and nonlinguistic (memory or learning) dysfunctions in dyslexia arise from a deficit in memory for serial-order information (i.e., the order in which items are presented within a sequence). 
proactive interference in dyslexia 4

This hypothesis was grounded on the observation that Hebb repetition learning, that is, improved recall for a repeated sequence of (verbal, visual or spatial) items over the course of an immediate serial recall task (Hebb, 1961), is impaired in adults with dyslexia. It has been shown experimentally that Hebb repetition learning can be considered a laboratory analogue of lexical acquisition, in the sense that acquiring a novel lexical form (e.g., the novel word "beejayeffemmelle") is closely related to learning a sequence of verbal items (e.g., B J F M L) over the course of repeated exposures (Page \& Norris, 2008, 2009). Following this rationale, Bogaerts, Szmalec, Hachmann, Page, and Duyck (submitted) went further to directly demonstrate that impaired Hebb learning of verbal serial information in dyslexia is associated with difficulties in acquiring novel lexical representations. These findings were very recently extended by Perham, Whelpley, and Hodgetts (2013), who observed impaired memory for syntactical information (potentially another instance of serial-order learning) in poor readers. Furthermore, three recent studies demonstrated that both children and adults with dyslexia have difficulties with short-term memory for order (i.e. retaining the serial position of an item within a list) but not, or not to the same extent, for item information (Hachmann et al., in press; Martinez Perez, Majerus, Mahot, \& Poncelet, 2012 ; Martinez Perez, Majerus, \& Poncelet, 2013). Importantly, these serial order impairments again show affected processing beyond the verbal domain, affecting memory for non-verbal materials too. These data are consistent with older studies from the seventies showing impairments for people with dyslexia in both visuospatial and verbal serial recall tasks (Bryden, 1972; Corkin, 1974).

The hypothesis that dyslexia originates from an underlying deficit in serial-order memory advances our understanding of the relation between the linguistic problems and the 
proactive interference in dyslexia 5

associated learning dysfunctions that are often observed in dyslexia. It is widely recognized that memory for serial-order information (or sequential memory) is involved in a variety of cognitive functions and therefore plays a crucial role in human cognition (e.g., Acheson \& MacDonald, 2009; Conway \& Christiansen, 2001; Conway \& Pisoni, 2008). This raises the question of whether impaired serial-order memory in dyslexia possibly leads to other, perhaps more subtle impairments that until now have remained unidentified. The current study focuses on one important phenomenon that emerges when the representation of serial-order information is affected, namely increased susceptibility to proactive interference.

\section{Proactive interference}

The term proactive interference (PI) refers to difficulties in retrieving information due to interference from memory traces that were stored prior to the to-be-remembered materials (Jonides \& Nee, 2006). PI is seen as an important source of forgetting in long-term-memory (Underwood, 1957; Wixted \& Rohrer, 1993), but more recent studies show that PI also affects retrieval from working memory (e.g., Dempster \& Corkill, 1999; Lustig, May, \& Hasher, 2001; May, Hasher, \& Kane, 1999; Suprenant \& Neath, 2009; Whitney et al., 2001). Retrieving information that has (temporarily) been stored in memory can occur in two ways: by active recall or by simple recognition (if a cue or trigger is presented). The influence of PI on active recall memory is nicely demonstrated by the fact that WM span is higher when the length of the span sequence is manipulated in a decreasing procedure (i.e. starting with sequences of 9 down to 3 items), compared with an increasing procedure (i.e. starting with sequences of 3 up to 9 items). In the latter, the standard span procedure, the largest set sizes are presented last, that is, after numerous other trials, and therefore 
proactive interference in dyslexia 6

suffer more from PI. Participants show increased span scores when PI on the most vulnerable, long sequences is reduced by reversing the sequence of trials so that the larger set sizes are presented first or, alternatively, by adding breaks between span trials (May et al., 1999). Although most studies investigating PI have made use of recall tasks, there is also much evidence that PI affects recognition memory negatively (e.g., Oztekin \& McElree, 2007; Petrusic \& Dillon, 1972; Szmalec, Verbruggen, Vandierendonck, \& Kemps, 2010). In the current study we used the $n$-back recognition task (Smith \& Jonides, 1997). In this task participants are instructed to indicate for each item (e.g., letters, pictures) in a list whether it matches the item that was presented $n$ positions earlier. To perform this task, participants are required to remember the $n$ most recently presented items in serial order. When new items are presented, participants need to update their WM, which means that they unbind the oldest item and bind the new item to a position in WM. We chose this task because it has been shown that the constant updating of items in WM prevents strong binding of those items to their contexts (i.e., their serial position in a list), which makes this recognition task a sensitive measure of PI (Szmalec et al., 2010).

Dual-process theories of recognition memory (see Yonelinas, 2002) assume that recognition memory can be subdivided into two distinct memory processes: familiarity matching and recollection. Familiarity matching refers to the fast and automatic assessment of whether an item has been encountered before (or feels familiar); recollection is the controlled retrieval of contextual details associated with an event. A common illustration of the distinction between these two memory processes is the experience of recognizing a person as being familiar but being unable to recollect the details about when or where the person was seen before. Familiarity matching and recollection were initially thought to 
underlie the recognition of items in long-term memory, but several studies suggest that the same processes also operate during access to information in WM (e.g., Goethe \& Oberauer, 2008; Oztekin \& McElree, 2007; Szmalec et al., 2010). In short-term recognition, and more specifically in the context of the n-back task, they can be defined as two dissociable processes that operate in parallel during item recognition: (1) a familiarity matching process that, driven by the degree of activation of items in long-term memory, indicates whether a recognition probe matches a representation in memory and (2) a recollection process which guides the retrieval of items from the direct access region of $\mathrm{WM}^{1}$ and provides more contextual information about when exactly the item was previously encountered (e.g., serial position). The quality of recollection directly depends on the strength of the bindings between the stimulus and the context in WM. Within this framework, PI represents a conflict in WM that is elicited when familiarity matching indicates that an item has been encountered before and thus competes for recognition, while the context-sensitive recollection process specifies that this item is old and does not belong to the to-be-memorized information (Jonides \& Nee, 2006; Oberauer, 2005). Here, it is important to note that only the context-sensitive recollection process depends on serial order (or, equivalently, position) memory in the sense that it involves memory representations of the items in their position of occurrence, whereas this is not the case for familiarity matching that just relies on the level of activation and is not context- or positionsensitive.

\footnotetext{
${ }^{1} \mathrm{WM}$ can be conceptualized as the activated part of long-term memory with a region of direct access where information is temporarily maintained in a directly accessible state (Oberauer, 2009).
} 
proactive interference in dyslexia 8

\section{Current study}

The aim of the current study was to investigate whether people with dyslexia and normal reading controls cope differentially with task conditions that elicit PI. Knowing that recollection from memory relies on order information and based on the evidence that dyslexic individuals show serial-order memory deficits (Martinez Perez et al., 2012, 2013; Szmalec et al., 2011), we hypothesized that recollection is less efficient in dyslexia and therefore that people with dyslexia will be more susceptible to PI, compared with a matched control group.

We investigated this hypothesis by making use of a 2-back task with black and white line drawings. In the n-back task, PI occurs when a new item does not match the item $n$ positions back but does match one of its neighbors (position $n+1$ or $n-1$ ). On these so-called luretrials participants are typically slower and less accurate. The familiarity-matching process signals that the item has been encountered previously, and the recollection process is needed to override the misleading activation from the familiarity process by providing the contextual evidence that the item was not encountered in the targeted n-back position. When the number of lure trials in the task increases, and thus more PI is elicited, participants typically engage in top-down adaptation strategies, such as a stronger reliance on the context-sensitive recollection process than on item familiarity (Oztekin \& McElree, 2007; Szmalec et al., 2010). Through these adaptation strategies the susceptibility to PI decreases.

To our knowledge, there have been only two memory studies using the n-back paradigm to investigate WM functioning in people with dyslexia (Beneventi, Tønnessen, Ersland, \& 
proactive interference in dyslexia 9

Hugdahl, 2010; Sela, Izzetoglu, Izzetoglu, \& Onaral, 2012). Using 0-back, 1-back and 2back variants of the n-back task with letter stimuli, Beneventi et al. (2010) found that children with dyslexia compared with controls had poorer performance on both the 1- and 2-back task, but not on the 0-back task that required to respond to the presence of a single target. Sela et al. (2012) did not find these behavioral group differences when using the nback task in an fNIR study with dyslexic university students (without phonological impairments) and matched controls, but did demonstrate lower maximum oxygenated hemoglobin levels in the left frontal lobe for the dyslexic group.

These findings point towards a WM deficit in dyslexia but, since WM demands were not further manipulated (e.g., through manipulations of PI by the introduction of lure trials as in our study), the cognitive mechanisms responsible for this decreased WM performance remain to be identified.

In the current experiment, we extend these findings by looking at performance of dyslexic adults on a 2-back picture task and, more importantly, by examining the influence that the introduction of lure trials has on performance. Participants had to complete two blocks of the n-back task: in the first block, only match and mismatch trials were presented; in the second block we introduced $n+1$ lure trials (see Figure1). These trials cause PI and therefore in the final block the recollection process is challenged by a competing familiarity signal. We predicted that people with dyslexia will make more errors overall, which would generalize the results in dyslexic children of Beneventi et al. (2010). Most importantly, knowing that the introduction of lure trials necessitates a shift towards recollection and hence imposes higher demands on serial-order memory, we predict that 2-back 
performance will suffer more from the introduction of lure trials in the dyslexic group than in the matched control group.

\author{
Method
}

\title{
Participants
}

Twenty-five adults with dyslexia and 25 matched controls were paid for participation. All were native Dutch speakers enrolled in higher education. Certificates of dyslexia were obtained from the university's official diagnostic centre. For further validation, we administered the Eén Minuut Test (Brus \& Voeten, 1979), assessing word reading proficiency, and the Klepel (van den Bos, Spelberg, Scheepsma, \& de Vries, 1994), a nonword reading test. The two groups were matched on IQ using the Fluid intelligence subscales from the Flemish version of the Kaufman Adolescent and Adult Intelligence Test (KAIT; Dekker, Dekker, \& Mulder, 2004; see Callens, Tops, \& Brysbaert, 2012). Table 1 shows that individuals with dyslexia and controls are matched on age and intelligence and only differed on the reading tests.

(Table 1 about here)

\section{Materials and Procedure}

The n-back task was administered in the third session of a set of experiments. The material of the n-back task consisted of 25 black and white line drawings that provide high naming agreement in Dutch, based on the norming study by Severens, Lommel, Ratinckx, and Hartsuiker (2005). Naming agreement was above $74 \%$ for all pictures $(M=89.04 \%)$ and their dominant name was always a monosyllabic word. Picture names had a length of two 
to five letters $(M=3.84)$, a frequency range between 1 and $73(M=30.35)$, log frequency 1 $1.8633(\mathrm{M}=1.36)$. The selected materials can be found in the Appendix.

The 2-back task consisted of two blocks of 94 trials each with a pause in the middle of each block (after 47 trials). Because this was a 2-back task, the first two trials of each block did not require a response, so that each block yielded 90 trials for analysis. The first block contained 30 match trials (i.e., the picture matched the picture presented two positions before) and 60 mismatch trials (i.e., the picture did not match the picture presented two positions before). The second block contained $13 n+1$ lure trials (i.e. target item does not match the item two positions back but does match the item three positions back). There were 30 match trials, 47 mismatch trials and 13 lures in this last block, which means that we kept the number of yes and no responses equal across blocks. For all mismatch trials, we made sure that no item was repeated earlier than 17 trials after its last appearance, by which the risk for PI from a previous encounter with that item is minimized (Szmalec et al., 2010). The occurrence of a particular drawing on a match, mismatch or lure trial was counterbalanced across all stimuli. Once the list order was created it was fixed and was exactly the same for each participant.

Drawings were presented one at a time, centered on the computer screen. Each picture stayed on the screen for $2000 \mathrm{~ms}$ and was followed by a blank screen for $1000 \mathrm{~ms}$. Participants were required to indicate as fast and accurately as possible whether a presented item matched the one presented 2 positions before by pressing the left (i.e., mismatch) or right key (i.e., match) on a response box. They were not informed about the presence of lures. 
A practice block of 47 trials preceded the experiment and was run with the same ratio of mismatch and match trials as block 1, but 25 different (uncontrolled) pictures from the same database were used. This practice block did not contain lure trials.

\section{Results}

Mean reaction times (RTs; correct trials only) and accuracy, averaged over match and mismatch trials, are displayed in Figure 2 as a function of the Block type and Group.

$R T s$

RTs were averaged over match and mismatch trials and analyzed by means of an ANOVA with Block type (without lures vs. with lures) and Group (control vs. dyslexia) as predictors. There was no main effect of either Group or Block type (both $F<1$ ), but there was a significant interaction effect between Block type and Group; $F(1,45)=5.05, p<0.05$, $\eta^{2}=0.10$ : the controls did not slow down significantly with the introduction of lure trials, $F(1,45)=1.10, p=0.30, \eta^{2}=0.02$, whereas the people with dyslexia did, $F(1,45)=4.40$, $p<0.05, \eta^{2}=0.09$ (see Figure 2a).

Planned comparisons further show no significant Group effect in both the block without lures $(F<1)$ and the block with lures; $F(1,45)=1.97, p=0.17, \eta^{2}=0.04$.

Comparing RTs to lure trials versus the average of match and mismatch trials (within the block with lures) by means of an ANOVA with Trial type and Group as predictors, we observed a significant lure-effect. This is, slower RTs for lure trials $(\mathrm{M}=1045.67$, $\mathrm{SD}=245.73)$ compared to the average of match and mismatch trials $(\mathrm{M}=814.33$, 
proactive interference in dyslexia 13

$\mathrm{SD}=148.96), F(1,45)=94.30, p<0.001, \eta^{2}=0.68$; there was however no main effect of Group nor a significant interaction between Trial type and Group $(F<1)$.

\section{Accuracy}

Accuracy was analyzed using the same ANOVA design. This yielded a significant main effect of Group across blocks, $F(1,45)=12.42, p<0.001, \eta^{2}=0.22$ : the dyslexic group $(\mathrm{M}=90.46 \%, \mathrm{SD}=0.036)$ performed worse than the control group $(\mathrm{M}=95.24 \%, \mathrm{SD}=0.056)$. The main effect of Block type was marginally significant, $F(1,45)=3.10, p=0.08$, indicating a trend towards worse performance for the block with lures $(\mathrm{M}=92.36 \%, \mathrm{SD}=0.066)$ compared to the block without lures $(\mathrm{M}=93.64 \%, \mathrm{SD}=0.05)$. Finally, the interaction effect between Block type and Group was not significant, $F(1,45)=2.26, p=.14, \eta^{2}=0.06$, but showed a trend similar to the RT results: the controls did not show a significant drop in accuracy with the introduction of lure trials, $F<1$, whereas the people with dyslexia did, $F(1,45)=5.00, p<0.05, \eta^{2}=0.10$ (see Figure $2 b$ ).

Planned comparisons further show that the Group difference was significant in both blocks:

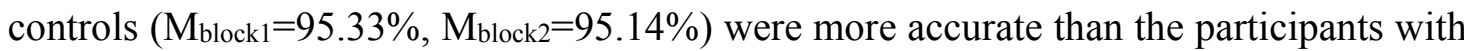
dyslexia $({\text { Mblock } 1=91.70 \%, \text { Mblock} 2=89.22 \%})$ in both blocks; $F(1,45)=7.08, p<0.05$ for block 1 and $F(1,45)=4.83, p<0.05$ for block 2 (see Figure $2 b$ ).

Also in terms of accuracy a significant lure-effect was observed, the accuracy for lure trials $(\mathrm{M}=77.57 \%, \mathrm{SD}=0.24)$ being lower compared with match and mismatch trials $(\mathrm{M}=92.37 \%, \mathrm{SD}=0.066), F(1,45)=18.45, p<0.001, \eta^{2}=0.29$. Similar to the $\mathrm{RT}$ data neither a significant main effect of Group nor an interaction with Group was observed $(F<1)$. 
proactive interference in dyslexia 14

\section{Discussion}

The current study investigated whether people with dyslexia have problems coping with task conditions that elicit PI. Previous research proposed that the linguistic and nonlinguistic problems associated with dyslexia may be best understood in terms of a core serial-order problem (Szmalec et al., 2011; Bogaerts et al., submitted). Since the contextsensitive recollection process that is used to overcome PI in an n-back updating task relies on a representation of the items in correct serial order, we hypothesized that recollection memory would be impaired in adults with dyslexia. In the current experiment, we compared their performance with that of a matched control group on a 2-back picture task with two blocks, one of which involved PI due to the use of lure trials. Importantly, the 2back picture task has no reading component and also no speeded element (presentation times are two seconds per item with a one second inter-trial interval).

In the first block without lure trials (i.e., only match and mismatch trials were presented), adults with dyslexia showed lower accuracy than controls. This group difference in accuracy could be expected given that familiarity matching and recollection are known to operate in parallel during item recognition and therefore even the block without lures can be assumed to draw on serial-order processing to some extent. Moreover, it is consistent with the results of Beneventi et al. (2010), who investigated WM performance in dyslexic children using 0-, 1-, and 2-back variants of the n-back task, but all without lures. ${ }^{2}$ In the second block, lure trials were introduced to increase PI and, as a consequence, increased the demands on order-sensitive recollection memory. In line with the predictions, our

\footnotetext{
${ }^{2}$ While our accuracy results in the block without lures are in line with the study of Benventi et al. (2010), we did not find a RT difference between groups on the 2-back task, whereas they did (see also Sela et al., 2012).
} 
results demonstrate that the reading impaired group was more severely affected by the introduction of lure trials compared with the control group: the RTs of the control group did not slow down significantly with the introduction of lure trials, whereas they did for the dyslexic group. This contributed to a reliable interaction between group and task. A similar finding was seen for accuracy in as much as the introduction of lures caused a clear drop in accuracy rates only for the dyslexic group; however, the interaction in this case was not reliable. These results suggest that people with dyslexia have a particular problem with order-sensitive recognition memory that is engaged to efficiently cope with the PI introduced by the presence of lure trials in block 2 . This is consistent with the predictions based on the hypothesis that dyslexia originates from an underlying deficit in serial-order memory (Szmalec et al., 2011). It also extends the recent findings on impaired short-term memory for order (Hachmann et al., in press; Martinez Perez et al., 2012, 2013) by showing similar problems with order memory within a WM updating paradigm.

Our use of nameable line drawings is a point that deserves some attention in the light of the problems with rapid automatized naming that are found in dyslexia (e.g., Norton \& Wolf, 2012). Although it is possible that stimuli were named subvocally, a basic naming speed deficit in the dyslexic group cannot be an alternative explanation for our results. Any naming component is present to the same extent in both blocks of the experiment. If the dyslexic group had basic naming speed difficulties, one would expect a group difference in RT in both blocks, and this was not the case.

In contrast to what one might expect given that the dyslexic group is more affected by the introduction of lures, no significant interaction between Trial type (lure vs. match+mismatch) and Group was found within the lure block. It should however be noted 
proactive interference in dyslexia 16

that the lure trials were meant as a between-block manipulation, using only 13 trials of this type. Therefore, the lack of a significant interaction effect might be due to insufficient statistical power. A systematic investigation of the performance of people with dyslexia on lure-trials themselves deserves attention in future research.

We argue that the serial-order approach may be helpful to better understand why dyslexia is often also associated with memory and learning deficiencies outside the domain of language. First, the hypothesis of a deficit in serial-order memory in dyslexia can nicely frame the WM findings in people with dyslexia. Frequently used tasks for short-term memory performance, such as digit span and other serial recall tasks, confound item storage and short-term memory for the order of the respective items. The reports of reduced memory span in dyslexia (e.g., Kibby, Marks, Morgan, \& Long, 2004; Smith-Spark \& Fisk, 2007) can therefore be framed in terms of a problem with the sequential, or order, component in the task, an explanation that is supported by the recent studies which dissociated the order and item components of WM (Hachmann et al., in press; Martinez Perez et al., 2012, 2013). The results of the current study, suggesting an increased susceptibility to PI in adults with dyslexia, can also well be framed within a general hypothesis relating to serial-order retention. 
proactive interference in dyslexia 17

\section{Acknowledgement}

This research was supported by the Research Foundation Flanders (FWO, B/12187/01), and by the Flemish Agency for Disabled Persons (VAPH). We are grateful to Valerie Van Hees and Charlotte De Langhe (vzw Cursief) for recruiting dyslexic volunteers. 
proactive interference in dyslexia 18

Appendix

Table with stimulus material.

\begin{tabular}{|c|c|}
\hline Picture name Dutch & Picture name English \\
\hline bad & bathtub \\
\hline boot & boat \\
\hline tak & branch \\
\hline koe & cow \\
\hline kast & dresser \\
\hline eend & duck \\
\hline ei & egg \\
\hline veer & feather \\
\hline vis & fish \\
\hline spook & ghost \\
\hline geit & goat \\
\hline hak & heel \\
\hline muis & mouse \\
\hline nest & nest \\
\hline peer & pear \\
\hline bord & plate \\
\hline vlot & raft \\
\hline touw & rope \\
\hline roos & rose \\
\hline sjaal & scarf \\
\hline stuur & steeringwheel \\
\hline tent & tent \\
\hline vaas & vase \\
\hline noot & walnut \\
\hline
\end{tabular}


proactive interference in dyslexia 19

$\begin{array}{ccr}\text { References } & \text { heks } & \text { witch } \\ \text { Acheson, D. J., \& } & & \text { MacDonald, }\end{array}$

M. C. (2009). Verbal working memory and language

production: Common approaches to the serial ordering of verbal information. Psychological Bulletin, 135(1), 50-68.

Beneventi, H., Tønnessen, F. E., Ersland, L., Hugdahl, K. (2010). Working memory deficit in dyslexia: behavioral and FMRI evidence. International Journal of Neuroscience, 120 (1), 51-59.

Bogaerts, L., Szmalec, A., Hachmann, M. W., Page, M. P. A., \& Duyck, W. (submitted). Dyslexia as a dis-order: the SOLID hypothesis. Annals of Dyslexia.

Brus, B. T., \& Voeten, M. J. M. (1979). Eén-Minuut-Test. Vorm A en B.

Schoolvorderingentest voor de technische leesvaardigheid, bestemd voor groep 4 tot en met 8 van het basisonderwijs. Verantwoording en Handleiding [One-Minute-Test. Forms A and B. Scholastic aptitude test for technical reading comprehension, for Group 4 up to 8 of primary school. Justification and manual]. Nijmegen, The Netherlands: Berkhout.

Bryden, M. P. (1972). Auditory-visual and sequential-spatial matching in relation to reading ability. Child Development, 43 (3), 824-832.

Callens, M., Tops, W., Brysbaert, M. (2012). Cognitive profile of students with an indication of dyslexia. PLOS ONE.

Conway, C. M., \& Christiansen, M. H. (2001). Sequential learning in non-human primates. Trends in Cognitive Sciences, 5, 539-546. 
proactive interference in dyslexia 20

Conway, C.M. \& Pisoni, D.B. (2008). Neurocognitive basis of implicit learning of sequential structure and its relation to language processing. Annals of the New York Academy of Sciences, 1145, 113-131.

Corkin, S. (1974). Serial-ordering deficits in inferior readers. Neuropsychologia, 12, 347354.

Dempster, F. N., \& Corkill, A. J. (1999). Interference and inhibition in cognition and behavior: Unifying themes for educational psychology. Educational Psychology Review, 11, 1-88.

Dekker R., Dekker P. H., Mulder J. L. (2004). Kaufman Adolescent and Adult Intelligence Test - Nederlandstalige Versie: Handleiding. PITS: Leiden.

De Kleine, E., \& Verwey, W. B. (2009). Motor learning and chuncking in dyslexia. Journal of motor behavior, 41 (4), 331-337.

Goethe, K., \& Oberauer, K. (2008). The integration of familiarity and recollection information in short-term recognition: Modeling speed- accuracy trade-off functions. Psychological Research, 72, 289-303.

Hachmann, W. M., Bogaerts, L., Szmalec, A., Woumans, E., Duyck, W., \& Job, R. (in press). Short-term memory for order but not for item information is impaired in developmental dyslexia. Annals of Dyslexia.

Hebb, D. (1961). Distinctive features of learning in the higher animal. In J. F. Delafresnaye (Ed.), Brain mechanisms and learning (pp. 37-46). Oxford, UK: Blackwell.

Jiménez-Fernández, G., Vaquero, J.M.M., Jiménez, L., \& Defior, S. (2011). Dyslexic children show deficits in implicit sequence learning, but not in explicit sequence 
proactive interference in dyslexia 21

learning or contextual cueing. Annals of dyslexia, 61, 85-110.

Jonides, J., \& Nee, E. (2006). Brain mechanisms of proactive interference in working memory. Neuroscience, 139, 181-193.

Kibby, M. Y., Marks, W., Morgan, \& S., Long, C. J.(2004). Specific Impairment in Developmental Reading Disabilities: A Working Memory Approach. Journal of Learning Disabilities, 37 (4), 349-363.

Lustig, May, \& Hasher. (2001). Working memory span and the role of proactive interference. Journal of Experimental Psychology: General, 130 (2), 199-207.

Lyon, G. R., Shaywitz, S. E., \& Shaywitz, B. A. (2003). A definition of dyslexia. Annals of Dyslexia, 53, 1-14.

Martinez Perez, T., Majerus, S., Mahot, A. \& Poncelet, M. (2012). Evidence for a specific impairment of serial order short-term memory in dyslexic children. Dyslexia, 18(2), 94-109.

Martinez Perez, T., Majerus S., Poncelet M. (2013). Impaired short-term memory for order in adults with dyslexia. Research in Developmental Disabilities, 34(7), 22112223

May, C. P., Hasher, L., \& Kane, M. J. (1999). The role of interference in memory span. Memory and Cognition, 27, 759-767.

Norton, E., \& Wolf, M. (2012). Rapid Automatized Naming (RAN) and Reading Fluency: Implications for Understanding and Treatment of Reading Disabilities. Annual Review of Psychology, 63, 427-452. 
proactive interference in dyslexia 22

Oberauer, K. (2005). Binding and inhibition in working memory - Individual and age differences in short-term recognition. Journal of Experimental Psychology: General, $134,368-387$.

Oberauer, K. (2009). Design for a working memory. Psychology of Learning and Motivation: Advances in Research and Theory, 51, 45-100.

Oztekin, I., \& McElree, B. (2007). Retrieval dynamics of proactive interference: PI slows retrieval by eliminating fast assessment of familiarity. Journal of Memory and Language, 57, 126-149.

Page, M. P. A., \& Norris, D. (2008). Is there a common mechanism underlying wordform learning and the Hebb repetition effect? Experimental data and a modelling framework. In A. Thorn \& M. Page (Eds.), Interactions between short-term and longterm memory in the verbal domain (pp. 136-156). Hove, UK: Psychology Press.

Page, M. P. A. \& Norris, D. (2009). A Model Linking Immediate Serial Recall, the Hebb Repetition Effect and the Learning of Phonological Word-forms. Philosophical Transactions of the Royal Society B, 364, 3737-3753.

Paulesu, E., Demonet, J. F., Fazio, F., McCrory, E., Chanoine, V., Brunswick, N., Cappa, S. F., Cossu, G., Habib, M., Frith, C. D., \& Frith, U. (2001). Dyslexia: Cultural diversity and biological unity. Science, 291(5511), 2165-2167.

Pavlidou, E. V., Kelly, M., \& Williams, J. M. (2010). Do children with developmental dyslexia have impairments in implicit learning? Dyslexia, 16(2), 143-161.

Pennington, B. F. (2006). From single to multiple deficit models of developmental disorders. Cognition, 101, 385-413. 
proactive interference in dyslexia 23

Perham, N., Whelpley, C., \& Hodgetts, H. (2013). Impaired memory for syntactical information in poor readers. Memory, 21 (2), 182-188.

Petrusic, W., \& Dillon, R. (1972). Proactive interference in short-term recognition and recall memory. Journal of Experimental Psychology, 95(2), 412-418.

Ramus, F. (2003). Developmental dyslexia: specific phonological deficit or general sensorimotor dysfunction? Current Opinion in Neurobiology, 13(2), 212-218.

Ramus, F., \& Szenkovits, G. (2008). What phonological deficit? Quarterly Journal of Experimental Psychology, 61, 129-141.

Sela, I., Izzetoglu M., Izzetoglu K., Onaral B. (2012). A working memory deficit among dyslexic readers with no phonological impairment as measured using the n-back task: an fNIR study. PLoS One, 7(11): e46527. doi: 10.1371/journal.pone.0046527.

Severens, E., Van Lommel, S., Ratinckx, E., \& Hartsuiker, R. J. (2005). Timed picture naming norms for 590 pictures in Dutch. Acta Psychologica, 119, 159-187.

Smith, E., \& Jonides, J. (1997). Working memory: A view from neuroimaging. Cognitive Psychology, 33, 5-42.

Smith-Spark, J. H., \& Fisk, J. E. (2007). Working memory functioning in developmental dyslexia. Memory, 15, 34-56.

Snowling, M. J. (2000). Dyslexia (2nd ed.). Oxford: Blackwell.

Stein, J. (2001). The magnocellular theory of developmental dyslexia. Dyslexia, 7, 12-36.

Surprenant, A. M., \& Neath, I. (2009). The 9 lives of short-term memory. In A. Thorn \& M. Page (Eds.), Interactions between short-term and long-term memory in the verbal domain (pp. 16-43). Hove, UK: Psychology Press. 
proactive interference in dyslexia 24

Szmalec, A., Verbruggen, F., Vandierendonck, A., \& Kemps, E. (2011). Control of interference during working memory updating. Journal of Experimental Psychology: Human Perception and Performance, 37, 137-151.

Szmalec, A., Loncke, M., Page, M. P. A., \& Duyck, W. (2011). Order or disorder? Impaired Hebb learning in dyslexia. Journal of Experimental Psychology: Learning, Memory, and Cognition, 37, 1270-1279.

Underwood, B. J. (1957). Interference and forgetting. Psychological Review, 64 (1), 49 60.

van den Bos, K. P., Spelberg, H. C., Scheepsma, A. J. M., \& de Vries, J. R. (1994). De Klepel. Vorm A en B. Een test voor de leesvaardigheid van pseudowoorden. verantwoording, handleiding, diagnostiek en behandeling [The Klepel. Forms A and B. A test for readability of pseudowords. Justification manual diagnostics and treatment]. Nijmegen, The Netherlands: Berkhout.

Vellutino, F. R., Fletcher, J. M., Snowling, M. J., \& Scanlon, D. M. (2004). Specific reading disability (dyslexia): what have we learned in the past four decades? Journal of Child Psychology and Psychiatry, 45 (1), 2-40.

Vicari, S., Marotta, L., Menghini, D., Molinari, M., \& Petrosini, L. (2003). Implicit learning deficit in children with developmental dyslexia. Neuropsychologia, 41, 108114.

Whitney, C., \& Cornelissen, P. (2005). Letter-position encoding and dyslexia. Journal of Research in Reading, 28, 274-301.

Wixted, J. T. \& Rohrer, D. (1993). Proactive-interference and the dynamics of free-recall. Journal of Experimental Psychology: Learning, Memory, and Cognition, 19, 1024-1039. 
proactive interference in dyslexia 25

Wimmer, H., Mayringer, H., \& Landerl, K. (2000). The double-deficit hypothesis and difficulties in learning to read a regular orthography. Journal of Educational Psychology, 92, $668-680$.

Yonelinas, A. (2002). The nature of recollection and familiarity: A review of 30 years of research. Journal of Memory and Language, 46, 441-517. 
proactive interference in dyslexia 26

Table 1

Means per group with standard deviations between brackets. Ns $=$ not significant. Group differences were tested with a one-way ANOVA on $d f(1,48)$. KAIT $=$ Kaufman Adolescent and Adult Intelligence Test, EMT= Eén Minuut Test.

\begin{tabular}{lccc}
\hline & Control $(\mathrm{n}=25)$ & Dyslexia $(\mathrm{n}=25)$ & Group difference \\
\hline Age & $21.22(1.50)$ & $20.60(1.44)$ & $n s$ \\
KAIT fluid & $109(9.89)$ & $106.92(10.93)$ & $n s$ \\
EMT (words/1 min.) & $101.64(10.46)$ & $83.29(18.92)$ & $p<.001$ \\
Klepel (nonwords/1 min.) & $65.12(12.41)$ & $44.71(13.03)$ & $p<.001$ \\
\hline
\end{tabular}


proactive interference in dyslexia 27

\section{Figure Captions}

Figure 1. Visualisation of the three types of trials.

Figure 2. Graph with mean RTs and accuracies as a function of the block type and group. 
proactive interference in dyslexia 28

Figure 1

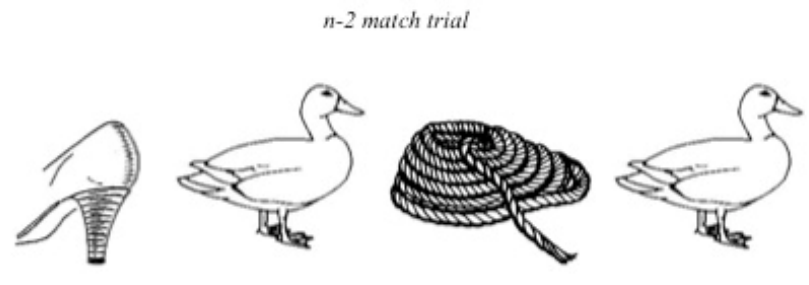

n-2 mismatch trial

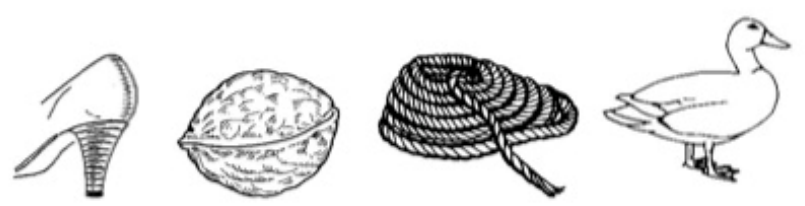

lure trial (type $n+l$

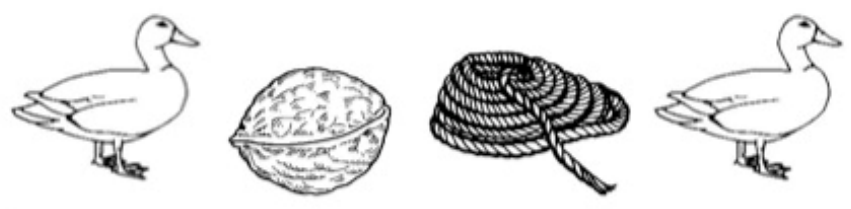


Figure 2
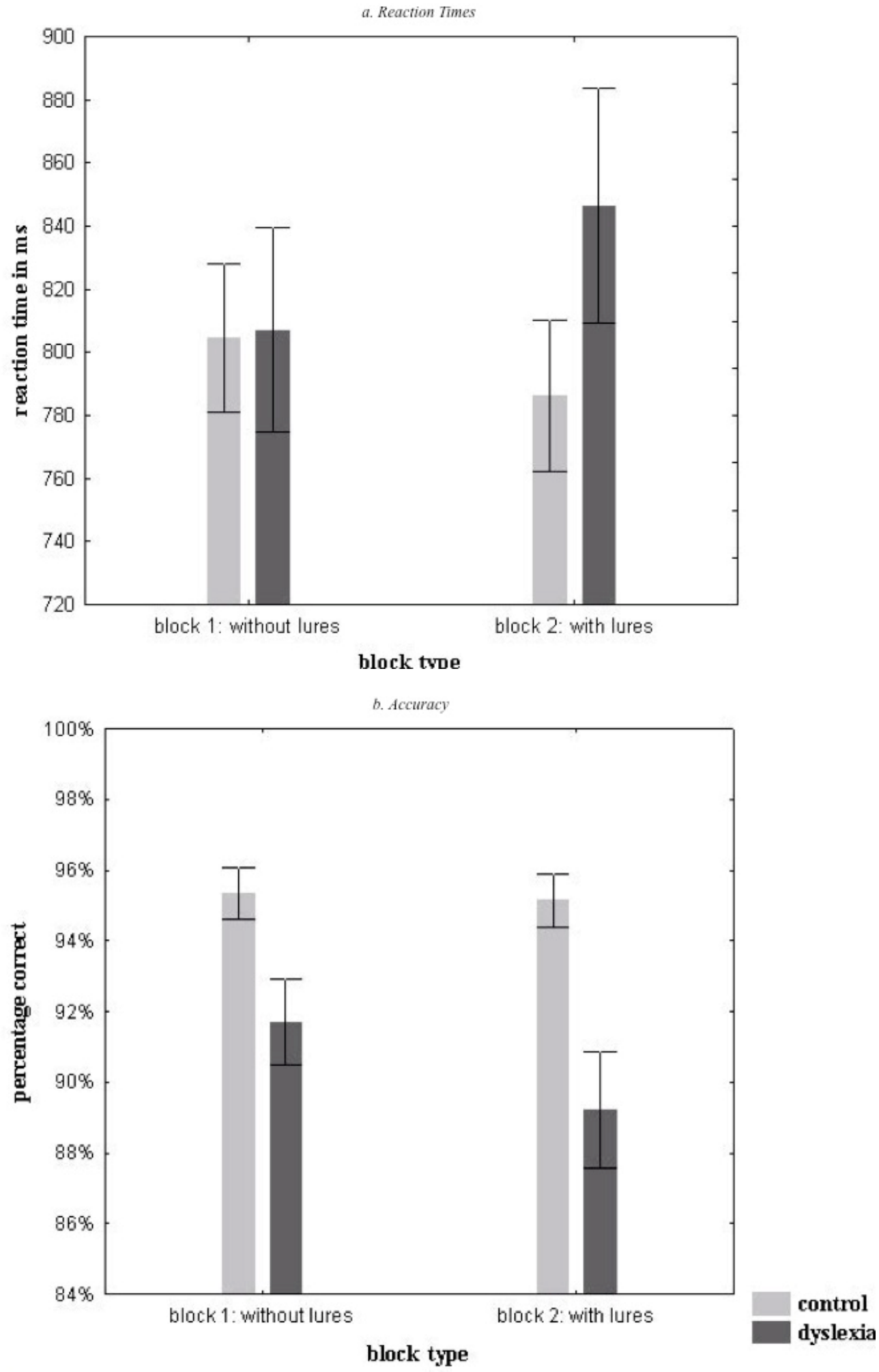
proactive interference in dyslexia 30 